\title{
ACTION OF ETHYLENEDIAMINETETRA-ACETIC ACID (EDTA) ON CARBENICILLIN-RESISTANT STRAINS OF PSEUDOMONAS AERUGINOSA
}

\author{
Elaine Barrett AND A. W. Asscher \\ K.R.U.F. Institute of Renal Disease, Welsh National School of Medicine, \\ Royal Infirmary, Cardiff
}

CARBENICILLIN is commonly used in the treatment of pseudomonas infections. Unfortunately, recent reports indicate the emergence of resistant strains (Bell and Smith, 1969; Lowbury et al., 1969). Since ethylenediaminetetra-acetic acid (EDTA) reverses the resistance of Pseudomonas aeruginosa to several antibiotics in vitro (Weiser, Asscher and Wimpenny, 1968), its effect on carbenicillinresistant strains of Ps. aeruginosa was studied.

\section{MATERIALS AND METHODS}

Strains of pseudomonas with two different kinds of carbenicillin resistance were studied, namely resistance produced by habituation in vitro and the resistance possessed by $P s$. aeruginosa strains nos. 1822 and 3425 , which contain a constitutive episomally mediated carbenicillinase (Fullbrook, Elson and Slocombe, 1970).

\section{Habituation procedure}

Three hospital strains, which were sensitive to $200 \mu \mathrm{g}$ per $\mathrm{ml}$ of carbenicillin, were subcultured serially on agar containing increasing concentrations of carbenicillin. The minimum inhibitory concentration (MIC) of carbenicillin for these strains was increased from $200 \mu \mathrm{g}$ per $\mathrm{ml}$ to $12,800 \mu \mathrm{g}$ per $\mathrm{ml}$ in seven stages.

\section{Detection of carbenicillinase activity}

Carbenicillinase activity was detected by estimating the carbenicillin concentration before and after incubation with whole cell and cell-free preparations of the bacterial strain under test. Carbenicillin was estimated by the cup-plate method in tests with Ps. aeruginosa no. NCTC10701.

\section{Measurement of reduction of carbenicillin resistance by EDTA}

The MIC for all strains of pseudomonas was determined in tubes of broth with doubling dilutions of antibiotic and an inoculum size of $10^{5}$ organisms per ml. Parallel estimations were also made in the presence of a subinhibitory concentration of the trisodium salt of EDTA $(200 \mu \mathrm{g}$ per ml). The number of tubes by which the EDTA shifted the MIC of carbenicillin was used as a measure of the reduction of carbenicillin resistance by EDTA.

\section{Effect of EDTA on carbenicillinase activity}

Cell-free extracts of $P$ s. aeruginosa strains nos. 1822 and 3425 were made by alternate freezing and thawing. These were mixed at a concentration of $c .2 \mathrm{mg}$ dry weight per $\mathrm{ml}$ with carbenicillin $(0.8 \mathrm{mg}$ per $\mathrm{ml})$ and incubated at $37^{\circ} \mathrm{C}$ with and without EDTA $(20 \mathrm{mg}$ per ml). 
Carbenicillin concentrations were measured at 4-min. intervals for $16 \mathrm{~min}$. by the hydroxylamine assay (Batchelor et al., 1961). The rates of decrease of carbenicillin concentration in the presence and absence of EDTA were then compared.

\section{Release of intracellular material}

EDTA causes a leakage of material that absorbs light at $260 \mathrm{~nm}$ (" $260-\mathrm{nm}$ absorbing material ") from sensitive bacterial cells (Key, Gray and Wilkinson, 1970). This material represents both the intracellular acid-soluble nucleotide pool and nuclear material (Neu, Ashman and Price, 1967). The rate of release of these substances is a measure of the susceptibility of the bacterial cell to the effect of EDTA and was determined in the following

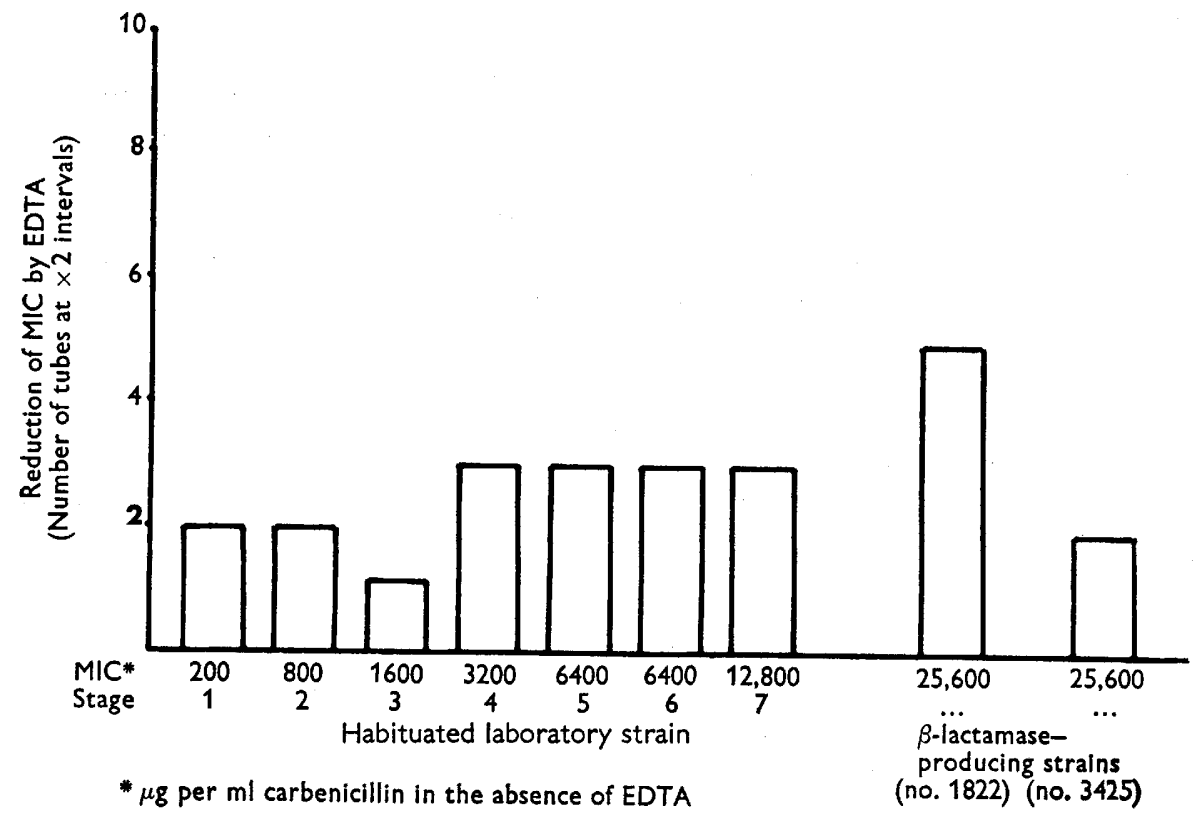

FIG. 1.-Reduction of carbenicillin resistance by $200 \mu \mathrm{g}$ per $\mathrm{ml}$ of EDTA in a habituated laboratory strain of Ps. aeruginosa at various stages of the development of its resistance. The figure also shows the reduction of resistance observed in the two $\beta$-lactamase-producing strains, nos. 1822 and 3425 .

manner. Organisms were grown overnight on nutrient agar slants (Oxoid DST Agar), washed off with physiological saline and centrifuged briefly to remove pieces of pellicle. They were then washed twice, and finally resuspended in physiological saline to a density of $10^{9}$ organisms per $\mathrm{ml} ; 3 \mathrm{ml}$ of this suspension was added to $20 \mathrm{ml}$ EDTA $(725 \mu \mathrm{g}$ per ml) in $0.01 \mathrm{M}$ borate buffer $(p \mathrm{H} \mathrm{7.4})$. At intervals of up to $90 \mathrm{~min}$. the action of EDTA was stopped by the addition of excess magnesium chloride. The suspensions were centrifuged for $45 \mathrm{~min}$. at $1000 \mathrm{~g}$ and passed through a millipore filter of pore size $0.45 \mu$. The extinction at $260 \mathrm{~nm}$ was then read on an SP1800 spectrophotometer.

\section{RESULTS}

Strains made resistant to carbenicillin by habituation

Carbenicillinase activity was not detected in any of these strains. The effect of EDTA on the MIC of carbenicillin for one of the habituated strains at the 
various stages of development of its resistance is shown in fig. 1. EDTA produces a virtually constant (2- to 3-tube) reduction of the MIC of carbenicillin at all stages of the development of habituated resistance. The results obtained with the two other strains that had been habituated in vitro were identical. High concentrations of EDTA are bactericidal. It is possible, therefore, that addition of the effects of EDTA and carbenicillin accounts for the constancy of the reduction of habituated carbenicillin resistance by EDTA. If this were so, it might be expected that the habituated resistant strains would be equally susceptible to a fixed dose of EDTA at all stages of the development of their

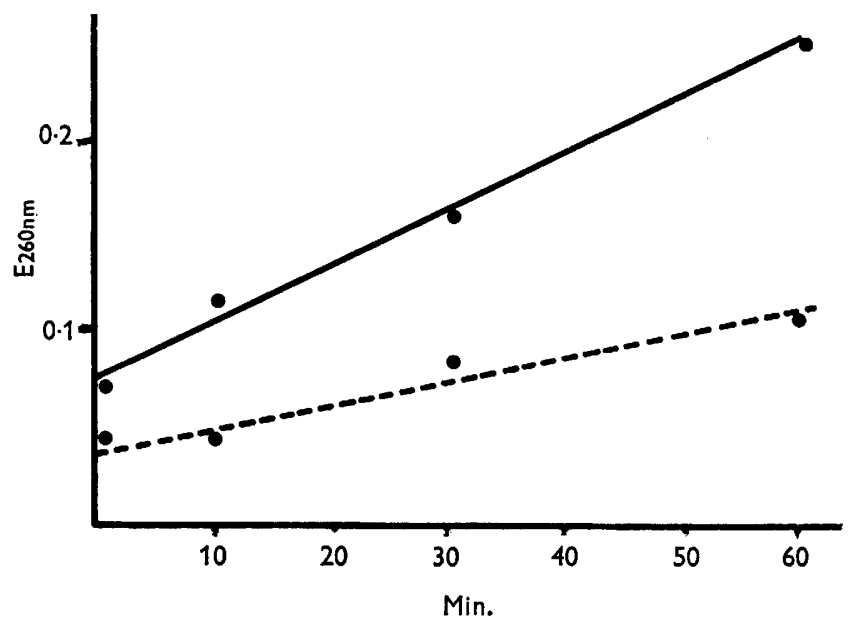

FIG. 2.-Release of 260-nm absorbing material on exposure to $725 \mu \mathrm{g}$ per ml EDTA by a carbenicillinsensitive strain of $P$ s. aeruginosa and a highly resistant variant of it produced by habituation in vitro. Sensitive strain; - - resistant strain. The difference is statistically significant $(\mathbf{P}<0.001)$.

resistance. This was not the case. As shown in fig. 2, the rates of release of 260-nm absorbing material were found to be significantly slower $(\mathrm{P}<0.001)$ from the habituated resistant strains than from their sensitive counterparts. Thus pseudomonas strains trained to tolerate carbenicillin are also more resistant to the action of EDTA, and the constant degree of reduction of carbenicillin resistance by EDTA cannot be attributed to a summation of the effects of EDTA and carbenicillin but must be ascribed to a synergistic effect of the EDTAcarbenicillin combination.

\section{Carbenicillinase-producing resistant strains}

It can be seen from fig. 1 that EDTA caused a marked (5-tube) reduction of carbenicillin resistance in one of these strains (Ps. aeruginosa no. 1822), whereas in the other (Ps. aeruginosa no. 3425) the reduction was less and fell within the range observed in the habituated resistant strains. EDTA had no effect on carbenicillinase activity, and the rate of release of $260-\mathrm{nm}$ absorbing material from the two strains did not differ significantly. 


\section{Discussion}

EDTA reduces carbenicillin resistance of Ps. aeruginosa irrespective of its degree or type. This may depend on the increase in bacterial permeability to penicillin produced by EDTA which enables more carbenicillin to reach its site of action (Hamilton-Miller, 1966). The development of habituated carbenicillin resistance was found to be associated with a reduction of the sensitivity of the bacterial cells to EDTA. This observation may clarify the mechanism of resistance produced by habituation in vitro. EDTA removes protein and lipopolysaccharide from the cell wall of Ps. aeruginosa (Rogers, Gilleland and Eagon, 1969). In Escherichia coli, loss of polysaccharide from the cell wall is associated with an increase in permeability, and resistance to EDTA is due to a change in the type of cell-wall lipopolysaccharide (Voll and Leive, 1970). Because the emergence of carbenicillin resistance on habituation in vitro is accompanied by the development of resistance to EDTA, it seems likely that habituated carbenicillin resistance is due to a change in type or increase in amount of cell wall lipopolysaccharide. Such a change in cell-wall composition might well form the basis of the "intrinsic" type of resistance shown by Ps. aeruginosa to carbenicillin (Sykes and Richmond, 1971).

Since EDTA does not affect the carbenicillinase activity of Ps. aeruginosa strains no. 1822 and 3425 , it seems likely that the reduction of carbenicillin resistance produced by EDTA in these strains, as in the habituated strains, also depends on an increase in bacterial permeability. Following exposure to EDTA, the rate of release of 260-nm absorbing substances from both of the carbenicillinase producing strains was similar. The more marked reversal of carbenicillin resistance observed in strain no. 1822 as compared with no. 3425 is probably accounted for by the observation that no. 1822 produces only a quarter of the carbenicillinase produced by no. 3425 (Fullbrook et al., 1970). Thus for a given increase in bacterial permeability produced by EDTA, the amount of carbenicillin reaching the carbenicillin " receptors " would be greater in strain no. 1822 , since less of the drug would be destroyed after entry into the bacterial cell.

\section{SUMMARY}

Sub-inhibitory concentrations of EDTA reduce the resistance of strains of Pseudomonas aeruginosa to carbenicillin in vitro. With strains made resistant by habituation, the extent of the reduction of carbenicillin resistance produced by a fixed subinhibitory dose of EDTA (200 $\mu \mathrm{g}$ per $\mathrm{ml})$ did not vary with the degree of resistance even though the development of this habituated resistance was associated with a loss of sensitivity of the bacterial cells to EDTA. This suggests (1) that the reduction of habituated carbenicillin resistance by EDTA is due to a synergistic effect of the EDTA-carbenicillin combination, and (2) that the development of habituated carbenicillin resistance in Ps. aeruginosa is due to a change in type or amount, or in both, of cell-wall lipopolysaccharide.

In carbenicillinase-producing resistant strains of Ps. aeruginosa, the amount of reduction of carbenicillin resistance by EDTA is variable and appears to be 
inversely related to the quantity of carbenicillinase produced by the bacterial strain.

We are grateful to Dr E. A. P. Croydon of Beecham Research Laboratories for providing cultures of PS. aeruginosa no. 1822 and 3425.

\section{REFERENCES}

Batchelor, F. R., Chain, E., Hardy, T., Mansford, K. R. L., and Rolinson, G. N. 1961. 6-Aminopenicillanic acid. 3. Isolation and purification. Proc. Roy. Soc., 154, 498.

BeLl, S. M., AND SMITH, D. D. 1969. Resistance of Pseudomonas aeruginosa to carbenicillin. Lancet, Lond., 1, 753.

FullbrooK, P. D., Elson, S. W., AND Slocombe, B. 1970. R-factor mediated $\beta$-lactamase in Pseudomonas aeruginosa. Nature, Lond., 226, 1054.

Hamilton-Miller, J. M. T. 1966. Damaging effects of ethylenediaminetetra-acetate and penicillins on permeability barriers in Gram-negative bacteria. Biochem.J., 100, 675.

Key, B. A., Gray, G. W., AND Wilkinson, S. G. 1970. The effect of ethylenediaminetetraacetate on Pseudomonas alcaligenes and the composition of the bacterial cell wall. Biochem. J., 117, 721.

Lowbury, E. J. L., Kidson, A., Lilly, H. A., Ayliffe, G. A. J., AND Jones, R. J. 1969. Sensitivity of Pseudomonas aeruginosa to antibiotics: emergence of strains highly resistant to carbenicillin. Lancet, 21, 448.

Neu, H. C., Ashman, D. F., ANd Price, T. D. 1967. Effect of ethylenediaminetetra-acetic acid-tris (hydroxymethyl) aminomethane on release of the acid-soluble nucleotide pool and on breakdown of ribosomal ribonucleic acid in Escherichia coli. J. Bact., 93, 1360.

Rogers, S. W., Gilleland, H. E., JR, AND EAGON, R. G. 1969. Characterization of a proteinlipopolysaccharide complex released from cell walls of Pseudomonas aeruginosa by ethylenediaminetetraacetic acid. Canad. J. Microbiol., 15, 743.

SYKeS, R. B., AND RICHMOND, M. H. 1971. R factors, beta-lactamase, and carbenicillinresistant Pseudomonas aeruginosa. Lancet, $2,342$.

Voll, MARY J., AND LeIVE, LORETTA 1970. Release of lipopolysaccharide in Escherichia coli resistant to the permeability increase induced by ethylenediaminetetraacetate. $J$. Biol. Chem., 245, 1108.

WeISER, R., AsSChER, A. W., AND WiMPENNY, JANICE 1968. In vitro reversal of antibiotic resistance by ethylenediaminetetra-acetic acid. Nature, Lond., 219, 1365. 